\title{
Functionalized magnetic MCM-48 nanoporous silica by cyanuric chloride for removal of chlorophenol and bromophenol from aqueous media
}

\author{
Mansoor Anbia · Sanaz Khoshbooei
}

Received: 30 October 2014/ Accepted: 6 December 2014/Published online: 16 December 2014

(C) The Author(s) 2014. This article is published with open access at Springerlink.com

\begin{abstract}
A novel adsorbent with magnetic $\mathrm{Fe}_{3} \mathrm{O}_{4}$ nanoparticles and melamine-based dendrimer amine functionalized mesoporous silica (MDA-magMCM-48) has been developed which would not destroy the pore structure and could supply a convenient way for separation of the adsorbent from water. The obtained adsorbent was characterized by XRD, SEM, TEM, FTIR, TGA and $\mathrm{N}_{2}$ adsorptiondesorption isotherm. The objective of this study was to evaluate the effectiveness of mesoporous MDA-magMCM48 material for the sorption of 4-chlorophenol (4-CP) and 4-bromophenol (4-BP). The effects of various operating parameters such as initial concentration, $\mathrm{pH}$ of the solution and contact time were thoroughly studied. From the sorption studies it is observed that the uptake of 4-CP $(239.55 \mathrm{mg} / \mathrm{g})$ was higher than that of 4-BP $(222.9 \mathrm{mg} / \mathrm{g})$. The Freundlich and Langmuir adsorption isotherms are used to model the equilibrium adsorption data.
\end{abstract}

Keywords Magnetic materials $\cdot$ Separation $\cdot \mathrm{Fe}_{3} \mathrm{O}_{4}$ nanoparticles

\section{Introduction}

Phenols and phenolic compounds are common contaminants in wastewaters generated from various industries

\section{Anbia ( $₫)$}

Research Laboratory of Nanoporous Materials, Faculty of Chemistry, Iran University of Science and Technology, 16846-13114 Tehran, Iran

e-mail: anbia@iust.ac.ir

\section{S. Khoshbooei}

Research Laboratory of Advanced Materials, Chemistry and Chemical Engineering Research Center of Iran,

P.O. Box 14335-186, Tehran, Iran such as high-temperature coal conversion, petroleum refining, resins olive oil production and plastics [1]. These compounds are toxic, carcinogenic, mutagenic and teratogenic. Due to the mentioned reasons, the presence of phenol in wastewater is a major problem for aquatic life and human health [2-4]. In order to remove phenolic compounds from wastewater streams, various treatment technologies such as adsorption [5, 6], chemical oxidation $[7,8]$, photodegradation $[9,10]$ and coagulation flocculation [11] are being used. Adsorption technology is currently being applied extensively to the removal of organic and inorganic micro-pollutants from aqueous solutions. Several adsorbents have been investigated earlier such as activated carbon [12], biosorbents [13], clays [14], zeolites [15] and synthetic resins [16, 17]. An ideal adsorbent should have features of strong affinity to target sorbate, large surface area and high pore volume with more binding sites. In recent years, ordered mesoporous molecular sieves such as SBA-n, MCM-41 and MCM-48 have attracted much attention as adsorbents [18]. MCM-48 presents as a more attractive candidate as an adsorbent or catalyst support than MCM-41, since the highly interwoven and branched structure provides many places where reactant molecules can avoid pore blockages [19]. Then, the regular pore network of MCM-48 provides more favorable mass transfer kinetics than the unidirectional pore system of MCM-41 leading to a perfect reactor for the synthesis of nanocomposites. Modification with ligands, such as amines, carbonates and organosulfides, on the surface of mesoporous materials is necessary to obtain specific adsorption and larger capacity [20, 21]. Silanol groups and amino groups are effective for the adsorption of organic compounds due to their high adsorption energy or potential charge association. In addition, the presence of free electron pairs on amine group within mesopores of MCM-48 
materials should lead to sorptive properties for weak acidic organic compounds in water [22]. Researchers have used ligands containing multi-amine groups in a chain [23, 24] or ligands involving dendrimer-amines [25] to increase removal efficiency of these compounds into the mesoporous structure. Melamine-based dendrimer amines (MDAs) are such ideal dendrimer ligands due to intensively binding amine sites and also to their enhanced hydrophilic silica surface compared to analogous adsorbents. MDAs were first reported in 2000 by Simanek and Zhang [26], but they have not been applied for phenolic compounds. The traditional adsorbents such as activated carbon are difficult to be separated after water treatment. Conventional methods such as centrifugation, precipitation and filtration are not only labor-consumptive but also uneconomical. Therefore, convenient and effective separation methods are in urgent demand. Magnetic adsorbent can be easily and rapidly separated from aqueous solutions under an external magnetic field due to their magnetic property and has the advantages of simplicity, high efficiency and sensitivity as well as low costs [18].Therefore, introducing $\mathrm{Fe}_{3} \mathrm{O}_{4}$ which features superparamagnetism into the prepared adsorbent is a good way to resolve the problem of separation.

In this study magnetically separable mesoporous silica (magnetic MCM-48) has been successfully synthesized and modified by melamine and has been used for the removal of halophenols from aqueous solutions.

\section{Experimental}

\section{Materials}

All the reagents used for experimental studies were of analytical grade. Tetraethylorthosilicate (TEOS $98 \%$ ), cetyltrimethyl ammonium bromide (CTAB, $99 \%$ ), 3-aminopropyltriethoxysilane (APTES, $98 \%$ ), $N, N$-di-isopropylethylamine (DIPEA), 2,4,6-trichloro-1,3,5-triazine (cyanuric chloride), ethylenediamine (EDA), iron(II) chloride tetrahydrate $\left(\mathrm{FeCl}_{2} \cdot 4 \mathrm{H}_{2} \mathrm{O}\right)$, Iron(III) Chloride $\left(\mathrm{FeCl}_{3}\right)$, $\mathrm{NH}_{4} \mathrm{OH}$, hydrochloric acid $(\mathrm{HCl}, 37 \%)$, methanol, dichloromethane, tetrahydrofuran, toluene, 4-chlorophenol (4-CP) and 4-boromophenol (4-BP) were from E. Merck (Darmstadt, Germany). Double-distilled water was used for the preparation of aqueous solutions and washing purposes.

Preparation of magnetic $\mathrm{Fe}_{3} \mathrm{O}_{4}$ nanoparticles

The $\mathrm{Fe}_{3} \mathrm{O}_{4}$ nanoparticles were prepared by chemical coprecipiation method [27]. $\mathrm{Fe}_{3} \mathrm{O}_{4}$ NPs were synthesized by mixing $\mathrm{FeCl}_{2} \cdot 4 \mathrm{H}_{2} \mathrm{O}(2.0 \mathrm{~g}), \mathrm{FeCl}_{3} \cdot 6 \mathrm{H}_{2} \mathrm{O}(5.2 \mathrm{~g})$ and $0.85 \mathrm{~mL}$ hydrochloric acid into $25 \mathrm{~mL}$ deionized water degassed with nitrogen beforehand. The mixture was added to a stirred $250 \mathrm{~mL} \mathrm{NaOH}$ solution $(1.5 \mathrm{M})$ with nitrogen gas passing continuously through the solution during the reaction. The produced magnetic NPs were rinsed with deionized water $(5 \times 50 \mathrm{~mL})$ and then resuspended in deionized water $(230 \mathrm{~mL})$. The generated NPs concentration was estimated to be about $10 \mathrm{mg} / \mathrm{mL}$.

\section{Synthesis of magnetic MCM-48 mesoporous silica}

The procedure for preparation of MCM-48 [28] was modified by introduction of nanoparticles in reaction mixture. Typically, $6 \mathrm{~g}$ cetyltrimethylammoniumbromide (CTAB), $35 \mathrm{~mL}$ deionized water and $0.549 \mathrm{~g} \mathrm{NaOH}$ were taken in flask then the mixture was added to $20 \mathrm{~mL}$ of the prepared $\mathrm{Fe}_{3} \mathrm{O}_{4}$ spheres slowly under vigorous stirring. After $3 \mathrm{~h}$ of stirring, $6.6 \mathrm{~mL}$ tetraethylorthosilicate (TEOS) was added drop wise and the stirring was continued until the gel became homogen. The whole synthesis was done in a heating mantle at $30-35{ }^{\circ} \mathrm{C}$. The mixture was filled into a Teflon-lined steel autoclave and statically heated at $135^{\circ} \mathrm{C}$ for $48 \mathrm{~h}$. The resultant was separated by magnetic field and washed several times with deionized water. After that it was vacuum dried at $70{ }^{\circ} \mathrm{C}$ and then calcined at $540{ }^{\circ} \mathrm{C}$ in air for $6 \mathrm{~h}$. This material was denoted as magMCM- 48 .

\section{Synthesis of amino-modified magMCM-48}

To prepare the amino-modified magMCM-48 sample, the procedure was carried out as follows [22, 29]: magMCM$48(2.0 \mathrm{~g})$ was suspended in $(70 \mathrm{~mL})$ toluene and the mixture was stirred for an hour and then to this mixture $(1.0 \mathrm{~g})$ APTES was added and the mixture was refluxed overnight. The solid product was separated by magnetic field. It was then soxhlet extracted with toluene to remove the silylating reagent residue. Finally it was dried at $70{ }^{\circ} \mathrm{C}$ under vacuum condition. This material was labeled as $\mathrm{NH}_{2}$-magMCM-48.

\section{Synthesis of MDA-magMCM-48}

The MDA-magMCM-48 was synthesized using cyanuric chloride and EDA according to a procedure similar that described previously in literature [30]. Cyanuric chloride (5.5 g: $30 \mathrm{mmol})$ and DIPEA (7.1 mL: $46 \mathrm{mmol})$ were dissolved in dried tetrahydrofuran $(300 \mathrm{~mL})$ and stirred at $0{ }^{\circ} \mathrm{C}$ for $3 \mathrm{~h}$ under argon atmosphere. $\mathrm{NH}_{2}-$ magMCM- 48 was added to the mixture and stirred for $24 \mathrm{~h}$ at $0{ }^{\circ} \mathrm{C}$. The chlorine atom in cyanuric chloride was easily replaced by the amine group of the APTES molecule and the DIPEA trapped that $\mathrm{HCl}$ formed during the substitution reaction. Then the mixture was separated by applying magnetic field and soxhlet extracted with tetrahydrofuran. The solid was transferred back into a clean flask containing a mixture of 
EDA (4 mL: $73.84 \mathrm{mmol}$ ), dissolved in dried tetrahydrofuran $(300 \mathrm{~mL})$ and refluxed for $24 \mathrm{~h}$. The material was separated by magnetic field, then soxhlet extracted with tetrahydrofuran. This resulting substance was denoted MDA-magMCM-48.

\section{Characterization}

The X-ray powder diffraction patterns were recorded on a Philips1830 diffractometer using $\mathrm{Cu}-\mathrm{K} \alpha$ radiation with a 0.02 step size and $1 \mathrm{~s}$ step time over the range of $1^{\circ}<2 \theta<10^{\circ}$. Adsorption-desorption isotherms of the synthesized samples were measured at $77 \mathrm{~K}$ on micrometrics model ASAP2010 sorptometer. Pore size distributions were calculated by the Barrett-Joyner-Halenda (BJH) method, while surface area of the sample was measured by BET method. The Fourier transform infrared spectra for the unmodified and modified samples were measured on a DIGILABFTS 7000 instrument under attenuated total reflection (ATR) mode using a diamond module. SEM micrographs were taken on a Philips-XL30 microscope. Thermo gravimetric analysis was used to determine the thermal stability of the synthesized materials and was carried out from room temperature to $873 \mathrm{~K}$ using a TGA/ DTA (Mettler Toledo 851) analyzer at a heating rate of $10 \mathrm{~K} / \mathrm{min}$ under $\mathrm{N}_{2}$ atmosphere.

\section{Adsorption studies}

In order to study the effect of various operating parameters such as $\mathrm{pH}$, initial concentration, adsorbent dose and contact time on the adsorption capacity of 4-cholorophenol and 4-boromphenol, batch sorption experiments were carried out. For single solute adsorption studies, model solutions of 4-CP and 4-BP were prepared by dissolving pure samples of the solutes in double distilled water. A known quantity of the adsorbent $(0.2 \mathrm{~g} / \mathrm{L})$ was taken in a stoppered conical flask $(100 \mathrm{~mL})$ containing $50 \mathrm{~mL}$ aqueous solution of 4-CP and 4-BP. The conical flasks were kept on a shaking incubator at ambient temperature $\left(25 \pm 2{ }^{\circ} \mathrm{C}\right)$ for $4 \mathrm{~h}$ to attain equilibrium. At the end of the adsorption process, the adsorbent was separated by magnetic field $(1.2 \mathrm{~T})$. The concentration 4-CP and 4-BP in the residual solution was analyzed by Lambda $25 \mathrm{UV} / \mathrm{VIS}$ spectrometer at wavelengths of 280 and $285 \mathrm{~nm}$, respectively.

In order to reduce the measurement errors, the UV absorption intensity for each equilibrium solution was measured in triplicates and the average value was used to calculate the equilibrium concentration; based on a standard calibration curve whose correlation coefficient square $\left(r^{2}\right)$ was 0.99 . The experimental error was observed to be within $\pm 2 \%$. The specific amount of solute (4-CP and 4-BP) adsorbed was calculated using Eq. (1):
$q_{\mathrm{e}}=\left(C_{0}-C_{\mathrm{e}}\right) V / W$,

where $q_{\mathrm{e}}$ is the adsorption capacity $(\mathrm{mg} / \mathrm{g})$ of the adsorbent at equilibrium; $C_{0}$ and $C_{\mathrm{e}}$ are the initial and equilibrium concentrations of solute $(\mathrm{mg} / \mathrm{L})$, respectively; $V$ is the volume of the aqueous solution $(L)$ and $W$ the mass $(\mathrm{g})$ of adsorbent used in the experiments.

\section{Results and discussion}

\section{Characterization of synthesized adsorbent}

SEM and TEM images of the magMCM-48 are presented in Fig. 1. As shown in Fig. 1, the magMCM-48 typically exhibits a sphere-like morphology and the particles of magMCM-48 were independent and not aggregated.

The low-angle XRD spectra for magMCM- $48, \mathrm{NH}_{2}-$ magMCM-48 and MDA-magMCM-48 are shown in Fig. 2. The XRD pattern of magMCM-48 exhibits strong (211) peak and proportional (220) peak intensities. In comparison between the XRD patterns before and after
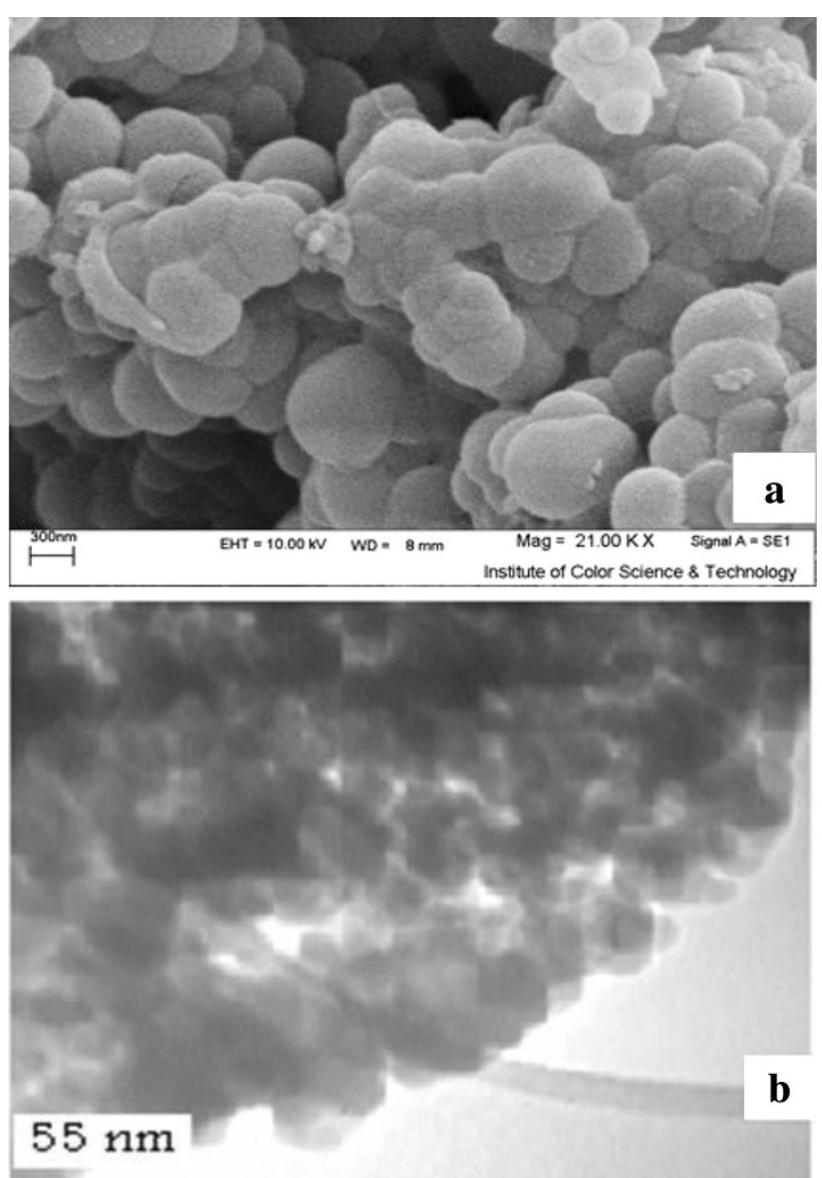

Fig. 1 Images of a scanning electron microscopy (SEM) and b transmission electron microscopy (TEM) of magMCM-48 


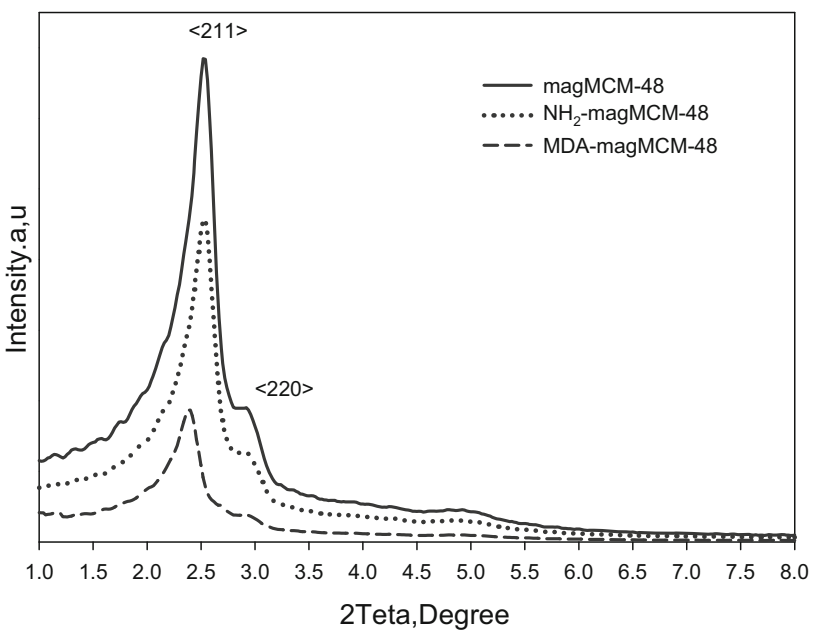

Fig. 2 XRD patterns of magMCM-48, $\mathrm{NH}_{2}-\operatorname{magMCM}-48$ and MDA-magMCM-48

modification with melamine-based dendrimer amine complexes, the peaks of magMCM-48 were remained. It was confirmed that the overall ordered structure of the mesoporous silica was not seriously perturbed. The intensities of the XRD peaks for $\mathrm{NH}_{2}-$ magMCM-48 and MDA-magMCM-48 were substantially lower than those measured for magMCM-48, which was probably caused by the pore filling effect of the magMCM-48 channels [31].

The amine groups and melamine-based dendrimers in the silicate frameworks were also identified using FT-IR. Figure 3 shows the FT-IR spectra of the modified sample along with the unmodified mesoporous magMCM-48. The typical $\mathrm{Si}-\mathrm{O}-\mathrm{Si}$ bands at 462,810 and $1,075 / \mathrm{cm}$ present in all samples are attributed to the condensed silica network [32]. magMCM-48 exhibits an absorption band at about $3,400 / \mathrm{cm}$, attributed to the $-\mathrm{OH}$ stretching vibrations of silanol groups. The band at $1,695 / \mathrm{cm}$ is probably due to $\mathrm{NH}_{2}$ bending, especially intensive for the $\mathrm{NH}_{2}$-magMCM48 sample, indicating the presence of primary amine. The stretching bands at 2,950 and $3,076 / \mathrm{cm}$ are attributed to asymmetric and symmetric $\mathrm{C}-\mathrm{H}$ stretching in the propyl chain. The band at $1,642 / \mathrm{cm}$ (MDA-magMCM-48 spectrum) is the evidence of an aromatic triazine ring in the MDA-magMCM-48 sample and confirms that the melamine-based dendrimer are formed [33]. These results confirm the successful functionalization of magMCM-48 with aminopropyl and melamine-based dendrimer groups.

Thermogravimetric analysis (TGA) curves for $\mathrm{NH}_{2}-$ magMCM-48 and the MDA-magMCM-48 samples depicted in Fig. 4 show slow but continuous weight loss. The weight loss observed below $150{ }^{\circ} \mathrm{C}$ in representative samples was associated with the desorption of water. The weight loss between 150 and $840{ }^{\circ} \mathrm{C}$ was used as the baseline amount for the organic moieties of each sample;

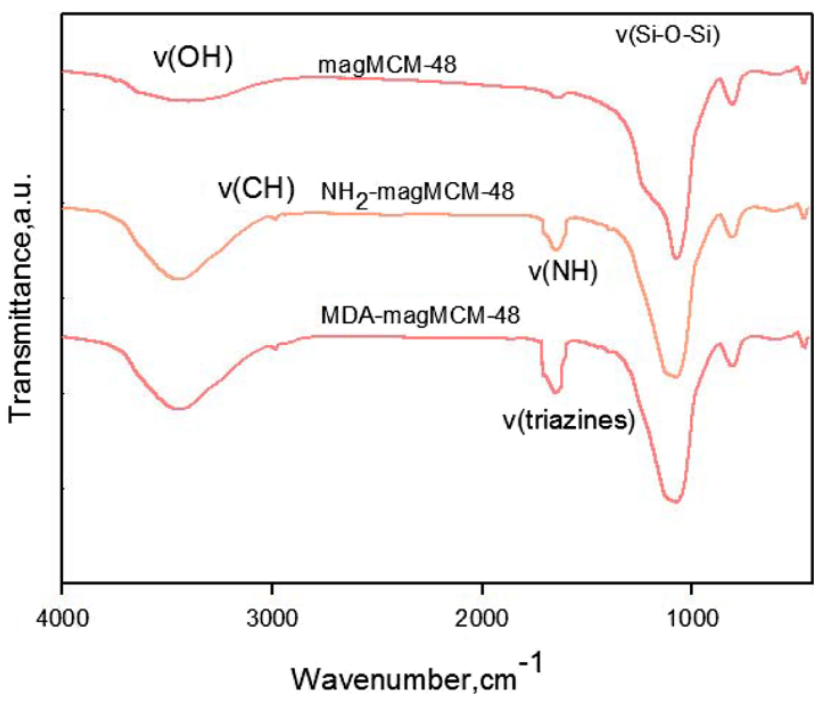

Fig. 3 FT-IR spectra of magMCM-48, $\mathrm{NH}_{2}-\operatorname{magMCM}-48$ and MDA-magMCM-48

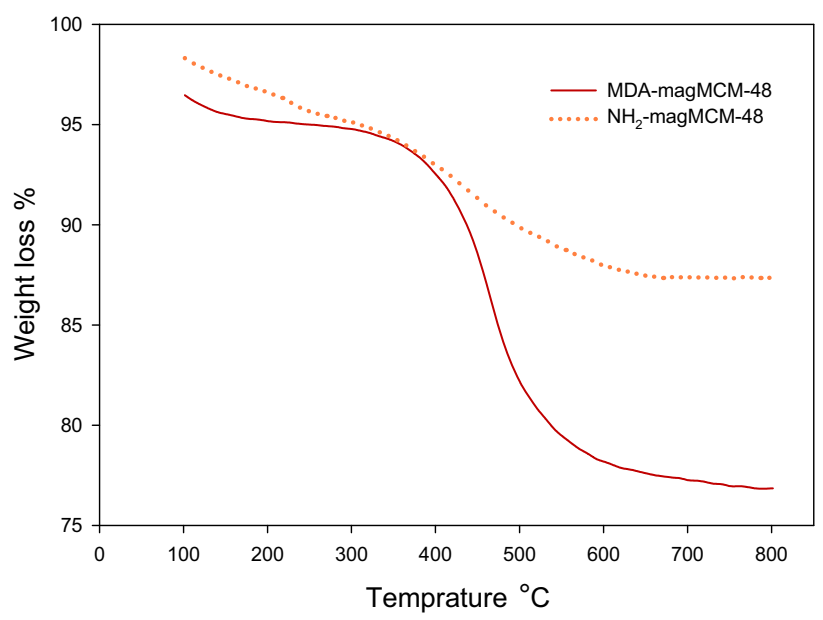

Fig. 4 Thermogravimetric curves of $\mathrm{NH}_{2}-\operatorname{magMCM}-48$ and MDA$\operatorname{magMCM}-48$

however, most of the weight loss above $600{ }^{\circ} \mathrm{C}$ is due to the dehydroxylation of the silicate networks. The aminopropyl loaded on the surface of magMCM-48 was calculated to be about $0.36 \mathrm{mmol} / \mathrm{g}(8.01 \%$ weight loss) in the $\mathrm{NH}_{2}-$ magMCM-48 sample and the amount of the dendrimer ligand was calculated to be about $0.69 \mathrm{mmol} / \mathrm{g}$ (17.49\% weight loss) on the surface of the MDA-magMCM-48 sample.

Figure 5 shows the adsorption/desorption isotherms of nitrogen at $77 \mathrm{~K}$ on MDA-magMCM-48. This isotherm exhibits a type IV profile according to the BET classification. In comparison with magMCM-48, decrease in the pore diameter values by about 4.20 and $3.46 \mathrm{~nm}$ are observed for $\mathrm{NH}_{2}-$ magMCM-48 and MDA-magMCM-48, 


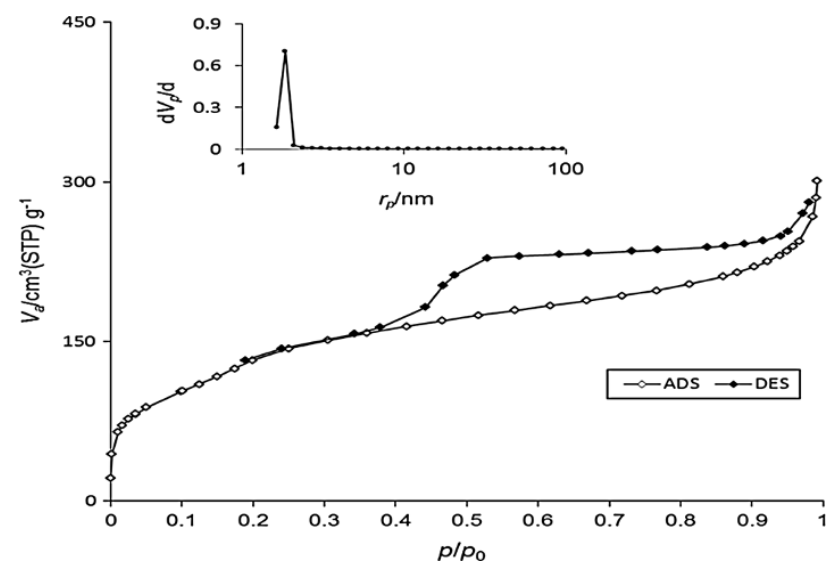

Fig. $5 \mathrm{~N}_{2}$ adsorption and desorption isotherms at $77 \mathrm{~K}$ of MDAmagMCM-48. The inset shows the BJH pore size distribution of MDA-magMCM-48 calculated from the desorption branch of the isotherm

respectively, which is due to functionalization inside the channels of MCM-48. The pores size distribution (BJH) analysis of nitrogen desorption isotherm (Fig. 5) shows one strong peak for the pore diameter $3.46 \mathrm{~nm}$ and this indicates that these compounds were having mesopores. The results for $\mathrm{N}_{2}$ adsorption-desorption containing the pore diameters, the BET surface and the total pore volumes of the calcined magMCM- $48, \mathrm{NH}_{2}-\mathrm{magMCM}-48$ and MDAmagMCM-48 samples are summarized in Table 1.

Adsorption studies

\section{Effect of chemical modification}

In order to evaluate the efficiency of the prepared adsorbents, the equilibrium adsorption of 4-CP and 4-BP was studied as a function of equilibrium concentration. The adsorption capacity of 4-CP and 4-BP on MDA-magMCM-48, $\mathrm{NH}_{2}-$ magMCM-48 and magMCM-48 is shown in Figs. 6 and 7. It is seen that the order of adsorption in terms of the amount adsorbed $(\mathrm{mg} / \mathrm{g})$ at different conditions is MDA-magMCM- $48>\mathrm{NH}_{2}-\operatorname{magMCM} 48>$ magMCM-48. MDA-magMCM-48 has demonstrated higher adsorption capacity $(239.55$ and $222.9 \mathrm{mg} / \mathrm{g}$ for $4-\mathrm{CP}$ and 4-BP, respectively) in comparison with $\mathrm{NH}_{2}-$ magMCM-48 $(102.5$ and $100 \mathrm{mg} / \mathrm{g})$ and the untreated mesoporous magMCM-48 (43 and $40 \mathrm{mg} / \mathrm{g} \quad 4-\mathrm{CP}$ and 4-BP, respectively).

The high adsorption capacity of MDA-magMCM-48 can be explained by several facts. This may be because of the hydrophobicity created by amine groups. It is also inferred that the presence of a free electron pair causes more interaction between 4-CP or 4-BP and adsorbent in MDA-magMCM-48. In other words, 4-CP and 4-BP are
Table 1 Textural properties of magMCM-48, $\mathrm{NH}_{2}-$ magMCM-48 and MDA-magMCM-48

\begin{tabular}{llll}
\hline Adsorbent & $d$ spacing $(\mathrm{nm})$ & $A_{\mathrm{BET}}\left(\mathrm{m}^{2} / \mathrm{g}\right)$ & $V_{\mathrm{p}}\left(\mathrm{cm}^{3} / \mathrm{g}\right)$ \\
\hline magMCM-48 & 4.6 & 812 & 0.65 \\
NH2-magMCM-48 & 4.2 & 725 & 0.52 \\
MDA-magMCM-48 & 3.46 & 511 & 0.44 \\
\hline
\end{tabular}

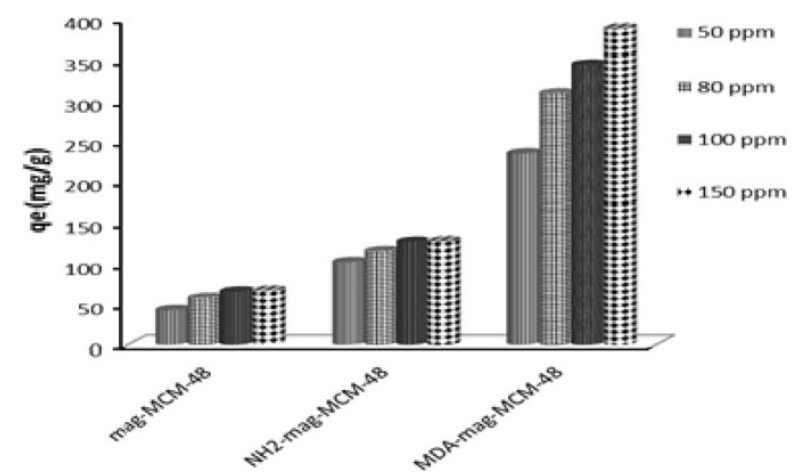

Fig. 6 Effect of initial concentration on uptake of 4-CP on MDAmagMCM-48, $\mathrm{NH}_{2}-\operatorname{magMCM} 48$, magMCM-48. (contact time $=4 \mathrm{~h}$, agitation speed $=250 \mathrm{rpm}$, adsorbent dosage $=0.2 \mathrm{~g} /$ $\mathrm{L}$, ambient temperature $=25 \pm 2{ }^{\circ} \mathrm{C}$ )

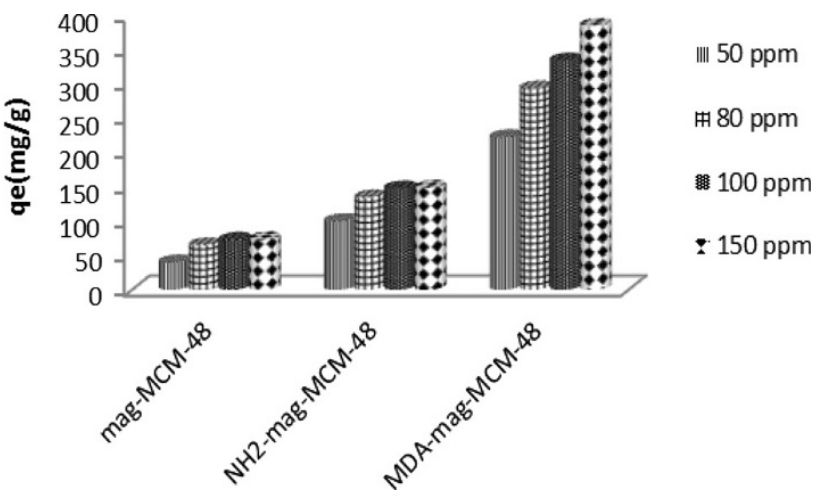

Fig. 7 Effect of initial concentration on uptake of 4-BP on MDAmagMCM-48, $\mathrm{NH}_{2}$-magMCM48, magMCM-48. (contact time $=4 \mathrm{~h}$, agitation speed $=250 \mathrm{rpm}$, adsorbent dosage $=0.2 \mathrm{~g} / \mathrm{L}$, ambient temperature $=25 \pm 2{ }^{\circ} \mathrm{C}$ )

weak acids and there are acid and alkaline interactions between amine groups and 4-CP and 4-BP.

\section{Effect of contact time and concentration}

In order to establish an equilibration time for the maximum uptake, the adsorption of 4-CP and 4-BP on MDA-magMCM-48 was studied as a function of contact time. The results are shown in Fig. 8. It is seen that the rate of uptake of the 4-CP and 4-BP is rapid at the beginning and $50 \%$ of adsorption is completed within $1 \mathrm{~h}$. Figure 8 also indicates 


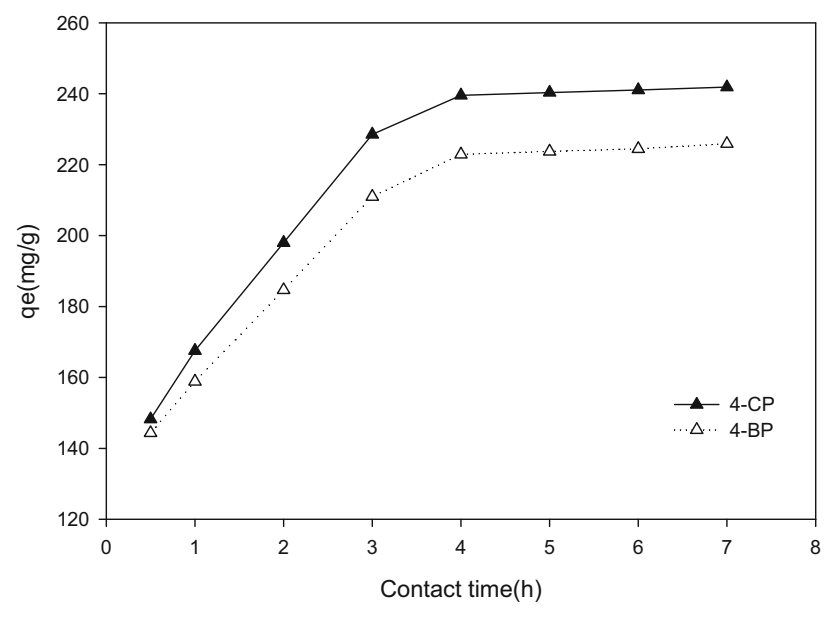

Fig. 8 Effect of contact time on uptake of 4-CP and 4-BP on MDAmagMCM-48 adsorbent (initial concentration $=50 \mathrm{mg} / \mathrm{L}$, agitation speed $=250 \mathrm{rpm}, \quad$ adsorbent dosage $=0.2 \mathrm{~g} / \mathrm{L}$ and ambient temperature $=25 \pm 2{ }^{\circ} \mathrm{C}$ )

that the time required for equilibrium is $4 \mathrm{~h}$. Thus, for all equilibrium adsorption studies, the contact period was kept $6 \mathrm{~h}$.

The effect of concentration on the equilibrium adsorption was also investigated as a function of initial concentration of 4-CP and 4-BP. The Figs. 6 and 7 show the adsorption capacity of 4-CP and 4-BP as function of adsorbent concentration. The MDA-magMCM-48 shows high adsorption capacity compared to magMCM-48 and $\mathrm{NH}_{2}-$ magMCM-48, which might be due to the grafted dendrimer amine groups on the surface of silica. The high adsorption capacity of MDA-magMCM-48 compared to $\mathrm{NH}_{2}-$ magMCM-48 is due to the multifunctional amine groups on the surface of the magMCM-48, thus possessing a higher loading capacity of the ligands than $\mathrm{NH}_{2}-$ magMCM-48.

\section{Effect of $p H$}

The $\mathrm{pH}$ of the aqueous medium is an important factor that may influence the uptake of the adsorbate. The effect of initial $\mathrm{pH}$ on the adsorption of 4-CP and 4-BP by MDAmagMCM-48 was studied. $\mathrm{NaOH}$ and $\mathrm{HCl}$ solutions were used to adjust the $\mathrm{pH}$ of the solution. The experimental results for the uptake of 4-CP and 4-BP on MDA-magMCM-48, in the $\mathrm{pH}$ range of 2-12, are shown in Fig. 9. It was observed that the relative uptake of 4-CP and 4-BP was significantly affected by $\mathrm{pH}$. The adsorption capacity of 4-CP and 4-BP remains nearly constant at $7<\mathrm{pH}<12$, while in acidic region the adsorption capacity for 4-CP and 4-BP decreases. This observation is due to the interactions of the protons with MDA-magMCM-48. There are acidalkaline interactions among adsorbates and MDA-

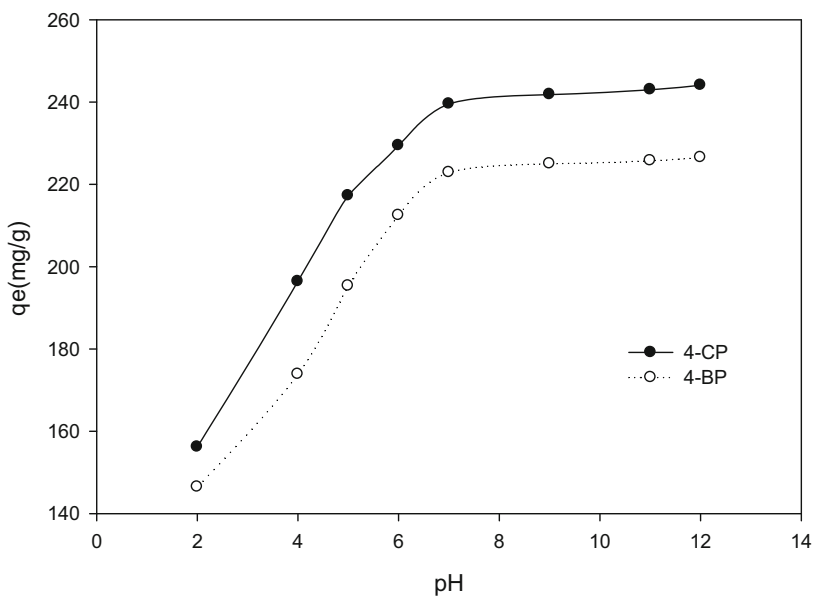

Fig. 9 Effect of $\mathrm{pH}$ on removal of 4-CP and 4-BP on MDAmagMCM-48 (initial concentration $=50 \mathrm{mg} / \mathrm{L}$, adsorbent dose $0.2 \mathrm{~g} /$ $\mathrm{L}$, contact time $=4 \mathrm{~h}$ )

magMCM-48. Therefore, the amount of adsorption depends on the acidic strength of the species. At low $\mathrm{pH}$ values, adsorption capacity decreases due to the presence of protons in solution which compete with 4-CP and 4-BP to be adsorbed on MDA-magMCM-48 species.

\section{Adsorption modeling}

Equilibrium studies were carried out to determine the adsorption capacity and equilibrium constant for 4-CP and 4-BP on MDA-magMCM-48. The distribution of solute between the liquid and solid phases is a measure of the distribution coefficient in the adsorption process and can be expressed by the Freundlich and Langmuir equations.

Adsorption equilibrium data, expressed by the mass of adsorbate adsorbed per unit weight of adsorbent, and liquid-phase equilibrium concentration of adsorbate are usually represented by adsorption isotherms, which is of importance in the design of adsorption systems. Two important isotherms, i.e., Freundlich [Eq. (2)] and Langmuir [Eq. (3)] isotherms, are selected in this study.

$q_{\mathrm{e}}=K_{\mathrm{f}} C_{\mathrm{e}}^{1 / n}$

$q_{\mathrm{e}}=q_{\mathrm{m}} b C_{\mathrm{e}} / 1+b C_{\mathrm{e}}$,

Table 2 Langmuir and Freundlich constants for adsorption of 4-CP and 4-BP on MDA-magMCM-48

\begin{tabular}{|c|c|c|c|c|c|c|}
\hline \multirow[t]{2}{*}{ Analyte } & \multicolumn{3}{|c|}{ Langmuir } & \multicolumn{3}{|c|}{ Freundlich } \\
\hline & $\begin{array}{l}q_{\mathrm{m}}(\mathrm{mg} / \\
\mathrm{g})\end{array}$ & $\begin{array}{l}b(\mathrm{~L} / \\
\mathrm{mg})\end{array}$ & $R^{2}$ & $\begin{array}{l}K_{\mathrm{f}}(\mathrm{mg} / \\
\mathrm{g})\end{array}$ & $\begin{array}{l}n(L / \\
m g)\end{array}$ & $R^{2}$ \\
\hline 4-CP & 320.21 & 2.32 & 0.940 & 196.53 & 6.37 & 0.970 \\
\hline 4-BP & 312.25 & 1.01 & 0.850 & 156.54 & 4.69 & 0.997 \\
\hline
\end{tabular}


Table 3 Comparison of adsorption capacity 4-CP and 4-BP onto some adsorbents

\begin{tabular}{|c|c|c|c|}
\hline Adsorbate & Adsorbent & $\begin{array}{l}q_{\mathrm{e}}(\mathrm{mg} / \\
\mathrm{g})\end{array}$ & References \\
\hline $\begin{array}{l}\text { 4-chlorophenol } \\
\text { (CP) }\end{array}$ & $\begin{array}{l}\text { Coconut shell charcoal } \\
\text { (CSC) }\end{array}$ & 54.65 & [36] \\
\hline $\begin{array}{l}\text { 4-bromophenol } \\
\text { (BP) }\end{array}$ & Fertilizer industry waste & 40.7 & {$[37]$} \\
\hline $\begin{array}{l}\text { 4-chlorophenol } \\
\text { (CP) }\end{array}$ & $\mathrm{NH}_{2}-\mathrm{SBA}-15$ & 141 & {$[38]$} \\
\hline $\begin{array}{l}\text { 4-bromophenol } \\
\text { (BP) }\end{array}$ & $\mathrm{NH}_{2}-\mathrm{SBA}-15$ & 114.6 & {$[38]$} \\
\hline $\begin{array}{l}\text { 4-chlorophenol } \\
\text { (CP) }\end{array}$ & MDA-Mag-MCM-48 & 239.55 & $\begin{array}{r}\text { Present } \\
\text { study }\end{array}$ \\
\hline $\begin{array}{l}\text { 4-bromophenol } \\
\text { (BP) }\end{array}$ & MDA-Mag-MCM-48 & 222.9 & $\begin{array}{l}\text { Present } \\
\text { study }\end{array}$ \\
\hline
\end{tabular}

where $q_{\mathrm{e}}(\mathrm{mg} / \mathrm{g})$ is the amount of 4-CP and 4-BP adsorbed per gram of MDA-magMCM-48 at equilibrium; $C_{\mathrm{e}}(\mathrm{mg} / \mathrm{L})$ the equilibrium concentration of 4-CP and 4-BP in solution; $k_{\mathrm{f}}(\mathrm{mg} / \mathrm{g})$ and $n(\mathrm{~L} / \mathrm{mg})$ are the Freundlich constants related to adsorption capacity and intensity, respectively; $q_{\mathrm{m}}(\mathrm{mg} / \mathrm{g})$ the maximum monolayer adsorption capacity; $b(\mathrm{~L} / \mathrm{mg})$ the constant related to the free energy of adsorption. The isotherm data have been linearized using the Freundlich and Langmuir equations. The data of these isotherms are provided in Table 2. It is clear that the adsorption isotherms can be fitted well using two isotherm models. The value of Langmuier and Freundlich for 4-CP and 4-BP are shown in Table 2. As it was explained earlier, 4-CP and 4-BP are weak acids and there are acid-alkaline interactions among 4-CP and 4-BP and MDA-magMCM48 species. Therefore, the amount of adsorption depends on the acidic strength of the 4-CP and 4-BP.

The adsorption capacities of MDA-magMCM- 48 for the adsorption of 4-CP and 4-BP were compared to those of some other adsorbent materials reported in literature under the same conditions $[34,35]$. Table 3 shows a comparison of the adsorbent capacity of various adsorbents for 4-CP and 4-BP. According to this table, MDA-magMCM-48 has a significant adsorption capacity for 4-CP and 4-BP compared to other adsorbents which is mentioned in the Table 3.

\section{Conclusions}

In this study magnetic modified mesoporous silica (MDAmagMCM-48) has been successfully synthesized; magnetic separability of this adsorbent makes it an effective and convenient adsorbent for the removal of halophenols from aqueous solutions. The results show that MDA-magMCM-
48 has a significant adsorption capacity for $\mathrm{CP}$ and $\mathrm{BP}$ compared to $\mathrm{NH}_{2}-$ magMCM-48 and untreated magMCM48. This may be due to the hydrophobicity created by the amine group and acid-alkaline interaction among halophenols and amine group of MDA-magMCM-48. The sorption of 4-CP on MDA-magMCM-48 was high compared to 4-BP. This could be attributed to the greater acidity of $\mathrm{CP}$, due to the greater electronegativity of the chlorine atom in comparison to the bromine atom, which leads to stronger interaction between the species and sorbent. It was observed that the $\mathrm{pH}$ of the aqueous solutions has considerable influence on adsorption of halophenols. Adsorption isotherm was also supported by Freundlich equilibrium adsorption model.

Acknowledgments The authors are thankful to Research council of Chemistry and Chemical Engineering Research Center of Iran (CCERC) and Iran National Science Foundation (INSF) for the financial support of this project.

Open Access This article is distributed under the terms of the Creative Commons Attribution License which permits any use, distribution, and reproduction in any medium, provided the original author(s) and the source are credited.

\section{References}

1. Mangrulkar, P.A., Kamble, S.P., Meshram, J., Rayalu, S.S.: Adsorption of phenol and o-chlorophenol by mesoporous MCM41. J. Hazard. Mater. 160, 414-421 (2008)

2. Khalid, M., Joly, G., Renaud, A., Magnoux, P.: Removal of phenol from water by adsorption using zeolites. Ind. Eng. Chem. Res. 43, 5275-5280 (2004)

3. Veeresh, G.S., Kumar, P., Mehrotra, I.: Treatment of phenol and cresols in upflow anaerobic blanket (UASB) process: a review. Water Res. 39, 154-170 (2005)

4. Aksu, Z.: Application of biosorption for the removal of organic pollutants : a review. Process Biochem. 40, 997-1026 (2005)

5. Banat, F.A., Al-Bashir, B., Al-Ashes, S., Hayajnesh, O.: Adsorption thermodynamics and kinetic investigation of aromatic amphoteric compounds onto different polymeric adsorbents. Environ. Pollut. 107, 391-398 (2000)

6. Dutta, S., Basu, J.K., Ghar, R.N.: Studies on adsorption of p-nitrophenol on charred saw-dust. Sep. Purif. Technol. 21, 227-235 (2001)

7. Wu, J., Rudy, K., Spark, J.: Oxidation of aqueous phenol by ozone and peroxidase. Adv. Environ. Res. 4, 339-346 (2000)

8. Hu, X., Lam, F.L., YCheung, L.M., Chania, K.F., Zhao, X.S., Lu, G.Q.: Removal of heavy metal ions from wastewater by chemically modified plant wastes as adsorbents:a review. Catal. Today 68, 129-133 (2001)

9. Wu, C., Lui, X., Wei, D., Fan, I., Wang, L.: Present status of management of nasopharyngeal carcinoma. Water Res. 35, 3927-3933 (2001)

10. Han, W., Zhu, W., Zhang, P., Zhang, Y., Li, L.: Photocatalytic degradation of phenols in aqueous solution under irradiation of 254 and 185 nm UV light. Catal. Today 90, 319-324 (2004)

11. Ozbelge, T.A., Ozbeze, O.H., Baskaya, S.Z.: Heavy metal adsorption onto agro-based waste materials. Chem. Eng. Process. 41, 719-730 (2002) 
12. Tancredi, N., Medero, N., Moller, F., Piriz, J., Plada, C., Cordero, T.: Phenol adsorption onto powdered and granular activated carbon, prepared from eucalyptus wood. J. Colloid. Interf. Sci. 279, 357-363 (2004)

13. Xing, B., McGill, W.B., Dudas, M.J.: Mechanism of slow desorption of organic compounds from sediments: a study using model sorbents. Environ. Sci. Technol. 28, 466-473 (1994)

14. Banat, F.A., Al-Bashir, B., Al-Asheh, S., Hayajneh, O.: Adsorption of phenol by bentonite. Environ. Pollut. 101, 391-398 (2000)

15. Kamble, S.P., Mangrulkar, P.A., Bansiwal, A.K., Rayalu, S.S.: Adsorption of phenol and o-chlorophenol on surface altered fly ash based molecularsieves. Chem. Eng. J. 138, 73-83 (2008)

16. Abburi, K.: Adsorption of phenol and p-chlorophenol from their single and bisolute aqueous solutions on Amberlite XAD-16 resin. J Hazard Mater. B. 105, 143-156 (2003)

17. Ku, Y., Lee, K.C.: Removal of phenols from aqueous solution by XAD-4 resin. J. Hazard. Mater. B. 80, 59-68 (2000)

18. Li, G., Zhao, Z., Liu, J., Jiang, G.: Effective heavy metal removal from aqueous systems by thiol functionalized magnetic mesoporous silica. J. Hazard. Mater. 192, 277-283 (2011)

19. Elias, V.R., Oliva, M., Vaschetto, E.G., Urreta, S.E., Eimer, G.A., Silvetti, S.P.: Magnetic properties of iron loaded MCM-48 Molecular sieve. J. Magn. Magn. Mater. 322, 3438-3442 (2010)

20. Burleigh, M.C., Markowitz, M.A., Spector, M.S., Gaber, B.P.: Amine-functionalized periodic mesoporous organosilicas. Chem. Mater. 13, 4760-4766 (2001)

21. Loy, D.A., Beach, J.V., Baugher, B.M., Assink, R.A., Shea, K.J., Tran, J., Small, J.: Dialkylene carbonate-bridged. Chem. Mater. 11, 3333-3341 (1999)

22. Anbia, M., Lashgari, M.: Synthesis of amino-modified ordered mesoporous silica as a new nano sorbent for the removal of chlorophenols from aqueous media. Chem. Eng. J. 150, 555-560 (2009)

23. Aguado, J., Arsuaga, J.M., Arencibia, A., Lindo, M., Gascón, V.: Aqueous heavy metals removal by adsorption on amine-functionalized mesoporous silica. J. Hazard. Mater. 163, 213-221 (2009)

24. Vasiliev, A.N., Golovko, L.V., Trachevsky, V.V., Hall, G.S., Khinast, J.G.: Adsorption of heavy metal cations by organic ligands grafted on porous materials. Micropor. Mesopor Mater 118, 251-257 (2009)

25. Jiang, Y., Gao, Q., Yu, H., Chen, Y., Deng, F.: Intensively competitive adsorption for heavy metal ions by PAMAM-SBA15 and EDTA-PAMAM-SBA-15 inorganic-organic hybrid materials. Micropor. Mesopor. Mater. 103, 316-324 (2007)

26. Zhang, W., Simanek, E.E.: Dendrimers based on melamine. Divergent and orthogonal, convergent syntheses of a G3 dendrimer. Org. Lett. 2, 843-845 (2000)

27. Li, J., Zhao, X., Shi, Y., Cai, Y., Mou, S., Jiang, G.: Mixed hemimicelles solid-phase extraction based on cetyltrimethylammonium bromide-coated nano-magnets $\mathrm{Fe} 3 \mathrm{O} 4$ for the determination of chlorophenols in environmental water samples coupled with liquid chromatography/spectrophotometry detection. J. Chromat. A 1180, 24-31 (2008)

28. Kim, T.W., Kleitz, F., Paul, B., Ryoo, R.: MCM-48-like large mesoporous silicas with tailored pore structure: facile synthesis domain in a ternary triblock copolymer-butanol-water system. JACS 127, 7601-7610 (2005)

29. Tarlani, A., Abedini, M., Nemati, A., Khabaz, M., Amini, M.M.: Immobilization of Keggin and Preyssler tungsten heteropolyacidson various functionalized silica. J. Colloid Interface Sci. 303, 32-38 (2006)

30. Acosta, E.J., Carr, C.S., Simanek, E.E., Shantz, D.F.: Engineering nanospaces: iterative synthesis of melamine-based dendrimers on amine-functionalized SBA-15 leading to complex hybrids with controllable chemistry and porosity. Adv. Mater. 16, 985-989 (2004)

31. Liang, Z., Fadhel, B., Schneider, C.J., Chaffee, A.L.: Stepwise growth of melamine based dendrimers into mesopores and their $\mathrm{CO} 2$ adsorption properties. Microporous Mesoporous Mater. 111, 536-543 (2008)

32. G. Socrates.: Infrared and Raman Characteristic Group Frequencies: tables and charts, 3rd edn. John Wiley \& Sons Ltd (2004)

33. Yoo, S., Lunn, J.D., Gonzalez, S., Ristich, J.A., Simanek, E.E., Shantz, D.F.: Engineering nanospaces: OMS/dendrimer hybrids possessing controllable chemistry and porosity. Chem. Mater. 18, 2935-2942 (2006)

34. Lin, S.H., Juang, R.S.: Adsorption of phenol and its derivatives from water using synthetic resins and low-cost natural adsorbents: a review. J. Environ. Manage. 3, 1-14 (2008)

35. Ahmaruzzaman, M.: Adsorption of phenolic compounds on lowcost adsorbents: a review. J. Adv. Colloid Interface Sci. 143, 48-67 (2008)

36. Kurniawan, T.A., Waihung, L., Repo, E., Sillanpä, M.E.: Removal of 4-chlorophenol from contaminated water using coconut shell waste pretreated with chemical agents. J. Chem. Technol. Biotechnol. 85, 1616-1627 (2010)

37. Bhatnagar, A.: Removal of bromophenols from water using industrial wastes as low cost adsorbents. J. Hazard. Mater. 139, 93-102 (2007)

38. Anbia, M., Amirmahhmodi, S.: Adsorption of phenolic compounds from aqueous solutions using functionalized SBA-15 as a nano-sorbent. Scientia Iranica C. 18, 446-452 (2011) 